Check for updates

Cite this: RSC Adv., 2019, 9, 17035

Received 3rd May 2019

Accepted 17th May 2019

DOI: 10.1039/c9ra03297e

rsc.li/rsc-advances

\section{Disproportionation-induced solid-state fluorescence in 6,13-dihydropentacenes $\uparrow$}

\author{
Tomoyuki Tajima, (DD *a Rai Sanda, ${ }^{a}$ Katsuya Nishihara, ${ }^{a}$ Hitoshi Shirai, ${ }^{a}$ \\ Yasuhiro Okuda, (D) ${ }^{\mathrm{b}}$ Akihiro Orita (iD ${ }^{\mathrm{b}}$ and Yutaka Takaguchi (DD *a
}

The thermally and photolytically induced disproportionation of 6,13-dihydropentacene derivatives into tetrahydropentacenes and pentacenes results in unique solid-state fluorescence. The fluorescence thereby depends on the molecular structure and the molecular arrangement in the solid state.
Disproportionation reactions are arguably one of the most important classes of organic reactions, especially in the context of coal liquefaction and aromatization, as well as Cannizzaro and biochemical reactions. However, reports on disproportionation reactions of aromatic hydrocarbons remain scarce. Stein and co-workers have reported the disproportionation of 9,10-dihydroanthracene $\left(>350{ }^{\circ} \mathrm{C}\right.$; liquid phase pyrolysis) into tetrahydroanthracene and anthracene. ${ }^{1}$ Pentacene has also been reported to undergo disproportionation at $320{ }^{\circ} \mathrm{C}$ in a horizontal vapor phase deposition furnace to produce 6,13dihydropentacene and polycondensed aromatic hydrocarbons. ${ }^{2}$ It has been postulated that $\mathrm{H}$-atom-transfer processes play a crucial role in such disproportion reactions. Indeed, H-atom transfer from 9,10-dihydroantharacene ${ }^{3,4}$ xanthene, ${ }^{4}$ fluorene, ${ }^{5}$ acridan, ${ }^{6}$ and other $\mathrm{H}$ donors $(\mathrm{D}-\mathrm{H})$ with weak $\mathrm{C}-\mathrm{H}$ bonds ${ }^{7}$ to unsaturated $\mathrm{H}$ acceptors has been widely explored.

On the other hand, the molecular design of $\pi$-conjugated systems is crucial for the development of new functional materials. Nevertheless, reports on $\pi$-conjugated systems exhibiting disproportionation-induced photoluminescence changes are relatively rare. Against this background, we decided to explore the utility of disproportionation reactions for the development of fluorescent chromic materials. Herein, we report the synthesis and disproportion of 6,13-dihydropentacene derivatives, as well as a detailed investigation into the fluorescence properties of the obtained compounds in the solid state.

The synthesis of $N, N^{\prime}$-bisalkyl-6,13-dihydropentacene $[2,3: 9,10]$ biscarboxyimides $\mathbf{3 a - c}$ is outlined in Scheme 1 . We have previously reported the synthesis of key starting material

${ }^{a}$ Graduate School of Environmental and Life Science, Okayama University, 3-1-1 Tsushima-naka, Kita-ku, Okayama 700-8530, Japan. E-mail: tajimat@cc.okayama-u. ac.jp; yutaka@cc.okayama-u.ac.jp

${ }^{b}$ Department of Applied Chemistry and Biotechnology, Okayama University of Science, 1-1 Ridai-cho, Kita-ku, Okayama 700-0005, Japan

$\dagger$ Electronic supplementary information (ESI) available. CCDC 1911683-1911686. For ESI and crystallographic data in CIF or other electronic format see DOI: 10.1039/c9ra03297e 6,13-dihydropentacene-2,3,9,10-tetracarboxylic acid (1) ${ }^{8}$ Tetracarboxylic acid 1 was converted into the corresponding anhydride (2) in good yield using a modification of the procedure reported by Qian and co-workers. ${ }^{9} \quad N, N^{\prime}$-Bisalkyl-6,13dihydropentacene[2,3:9,10] biscarboxyimides $3 \mathbf{3 a - c}$ were then obtained in 20-64\% yield by stirring anhydride 2 under reflux in the presence of the corresponding amines. The structure of the obtained dihydropentacene bisimides was confirmed by ${ }^{1} \mathrm{H}$ and ${ }^{13} \mathrm{C}$ NMR spectroscopy, IR spectroscopy, FAB mass spectrometry, and elemental analysis. The ${ }^{1} \mathrm{H}$ NMR spectrum of $3 \mathrm{a}$ in $\mathrm{CDCl}_{3}$ shows a singlet at $4.36 \mathrm{ppm}$, which was assigned to the central ring of dihydropentacene. In the aromatic region, two singlets appear at 8.03 and $8.23 \mathrm{ppm}$, which were attributed to the naphthalene ring. The ${ }^{13} \mathrm{C}$ NMR of 3a displays 13 signals, including five aromatic carbon atoms (123.5, $128.0 \times 2$, 134.4, 138.4, and $168.3 \mathrm{ppm}$ ) for the naphthalene ring, one carbonyl carbon atom (186.3 ppm), and one $\mathrm{sp}^{3}$-hybridized carbon atom of the central ring (38.5 ppm). In general, the spectra of $3 \mathbf{a}-\mathbf{c}$ are very similar.

Subsequently, we examined the disproportionation reaction of dihydropentacene 3a in the solid state (Scheme 2). Interestingly, upon heating solid 3a from room temperature to $230^{\circ} \mathrm{C}$, the color of the solid changed from colorless to green. To elucidate the origin of this green material, we investigated the absorption features of a thin film of $\mathbf{3 a}$ before and after heating $\left(250{ }^{\circ} \mathrm{C} ; 3 \mathrm{~h}\right)$. In the difference spectrum of 3a (Fig. 1), the positive absorption bands at 523, 560, and $611 \mathrm{~nm}$ were

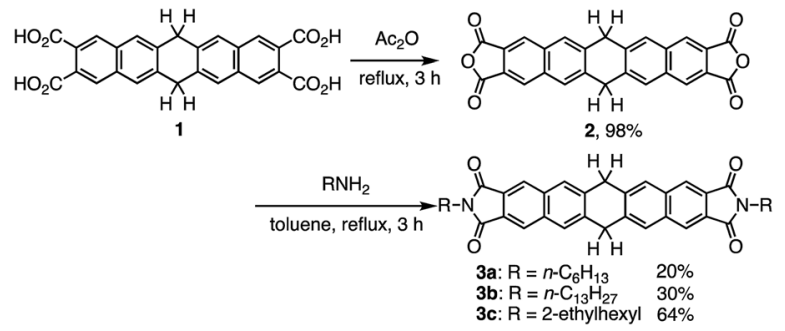

Scheme 1 Synthesis of $N, N^{\prime}$-bisalkyl-6,13-dihydropentacene $[2,3: 9,10]$ bis-carboxyimides $3 a-c$. 


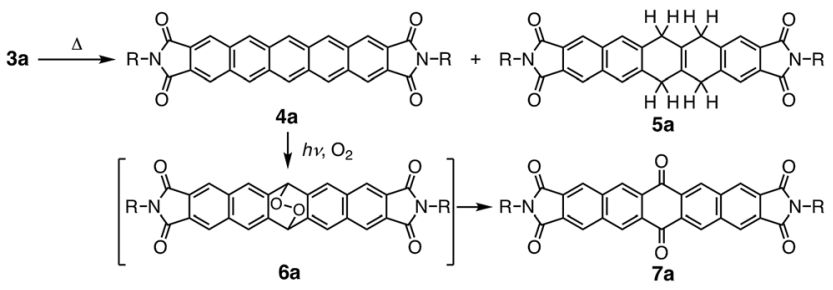

Scheme 2 Disproportionation reaction of dihydropentacene $3 a$ and decomposition of pentacene derivative $4 a$.

attributed to an expansion of the $\pi$-conjugated system. A comparison with the absorption spectrum of independently synthesized $N, N^{\prime}$-bispentylpentacene[2,3:9,10]biscarboxyimide (4a) revealed very similar features. The formation of pentacene derivative 4a was also confirmed by ${ }^{1} \mathrm{H}$ NMR spectroscopy (Fig. S1 $\dagger$ ). After heating $\left(250^{\circ} \mathrm{C} ; 40 \mathrm{~min}\right)$, the main signals were assigned to the starting material (3a), and the new signals suggested a conversion $<7 \%$. The ${ }^{1} \mathrm{H}$ NMR spectrum in $\mathrm{CDCl}_{3}$ showed three singlets at $8.50,8.94$, and $9.12 \mathrm{ppm}$, which were assigned to the protons attached to the pentacene core, respectively. Moreover, three singlets for aromatic protons (8.06, 8.22, and $8.39 \mathrm{ppm})$ and two singlets for methylene protons (4.27 and $4.81 \mathrm{ppm}$ ) were observed for tetrahydropentacene derivative 5a. Upon exposure to air, the signals of 4a disappeared and two singlets at 8.56 and $9.14 \mathrm{ppm}$ appeared, which were assigned to pentacene quinone $7 \mathrm{a}$, i.e., the oxidation product of pentacene $4 \mathbf{a}$ (Fig. $S 2 \dagger$ ). ${ }^{8 a, 10}$ An integral 5a : 7a ratio of $1: 1$ was estimated. These results strongly indicate that the thermal reaction of dihydropentacene $3 \mathbf{a}$ affords pentacene 4a and tetrahydropentacene $\mathbf{5 a}$ (Scheme 2).

Moreover, we discovered that $N, N^{\prime}$-bisalky-6,13dihydropentacene[2,3:9,10]bis-carboxyimide 3a exhibits solidstate fluorescence (Fig. 2); under illumination with UV light $\left(\lambda_{\mathrm{ex}}=365 \mathrm{~nm}\right)$, bright blue fluorescence was observed. Interestingly, upon heating $\mathbf{3 a}$ in solid state from room temperature to $230{ }^{\circ} \mathrm{C}$, the color of the apparent fluorescence gradually changed from bright blue to yellow and then red (Fig. 2a). Such phosphorchromaticity was observed for both film and crystalline samples (Fig. 2b), and the original color was not recovered even after cooling to room temperature. The differential scanning calorimetry (DSC) cooling and heating curves of 3a showed no peaks between room temperature and $270{ }^{\circ} \mathrm{C}$ (Fig. S3†). In the case of $\mathbf{3 b}$ and $\mathbf{3} \mathbf{c}$, similar fluorescence color changes were

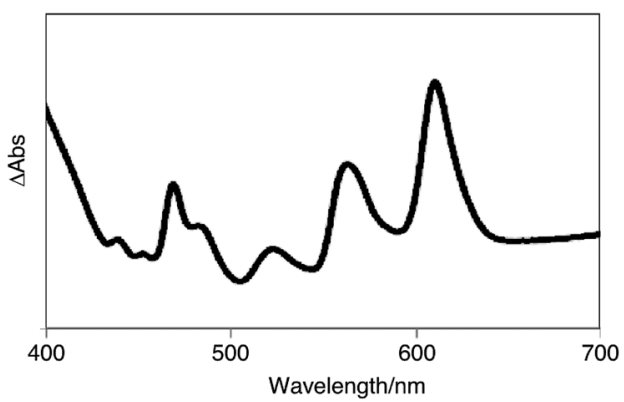

Fig. 1 The absorbance difference spectrum of a thin film of 3a before and after the heating.

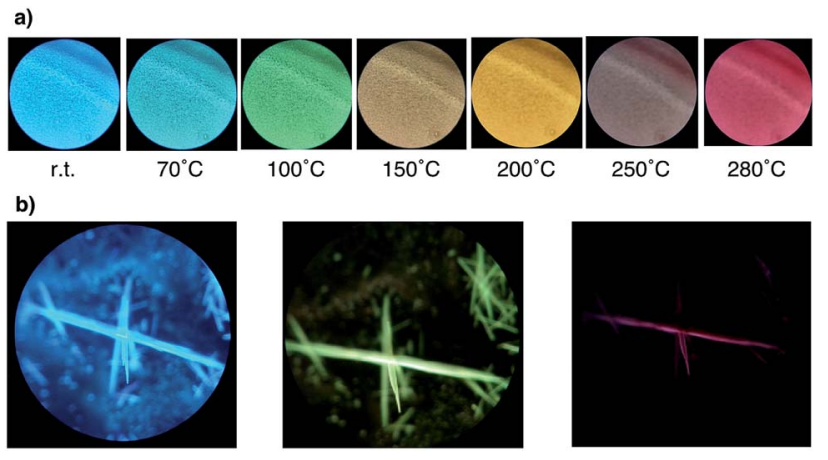

Fig. 2 (a) Apparent fluorescence color change of a 3a film with the increasing temperature. (b) Apparent fluorescence color change of crystals of $3 a$.

observed, while the crystal appearance changed from transparent to opaque. Polarized optical microscopy images revealed rough and cracked surfaces of the crystals of $\mathbf{3 b}$ and $\mathbf{3 c}$ after heating (Fig. S4†).

We also observed significant changes in the fluorescence spectra of a thin film of 3a with increasing temperature (Fig. S5†). The intensity of the fluorescence of the naphthaleneimide chromophore $(300-550 \mathrm{~nm})$ decreased with increasing temperature, while the intensity of the new fluorescence band at $638 \mathrm{~nm}$, which was assigned to a pentacene chromophore, increased. The decaying emission of the naphthaleneimide skeleton may be explained in terms of an energy transfer from 3a to $\mathbf{4 a} .^{11}$

Fig. S6 $\dagger$ shows the concentration-dependent emission spectra of 3a in $\mathrm{CHCl}_{3}$. At a concentration of $1.9 \times 10^{-4} \mathrm{M}$, a monomer emission band from the naphthaleneimide moiety was observed at 390 and $400 \mathrm{~nm}\left(\lambda_{\mathrm{ex}}=280 \mathrm{~nm}\right)$. Upon increasing the concentration of $3 \mathrm{a}$ beyond $7.7 \times 10^{-4} \mathrm{M}$, the fluorescence intensity of the naphthaleneimide moieties decreased and two new excimer emission bands emerged at approximately 440 and $460 \mathrm{~nm}$ with growing intensity. These results indicate that the solid-state fluorescence at $440 \mathrm{~nm}$ does not correspond to monomer emission, but to aggregate emission.

In order to determine the molecular conformation in the crystals and rationalize the observed reactivity, a single-crystal X-ray diffraction analysis was carried out (Fig. 3). Depending on the solvent, two different crystalline structures were identified in the case of 3a. A structural analysis of single crystals of 3a-c grown from benzonitrile solutions revealed a planar central six-membered ring of the dihydropentacenes (Fig. 3a, and S8 $\dagger$ ). The bond angle sums of the central six-membered rings are close to $720^{\circ}$. Numerous hitherto reported crystal structures are characterized by flattened boat conformations for dihydroanthracene and dihydropentacene derivatives, whereas the preferred conformation of dihydroaromatics should be a planar according to a theoretical study. ${ }^{12}$ In fact, there are a few crystallographic reports on dihydroanthacene $e^{13}$ and dihydropentacene ${ }^{14}$ skeletons with a planar geometry. In contrast, the structural analysis for crystals of 3a grown from 


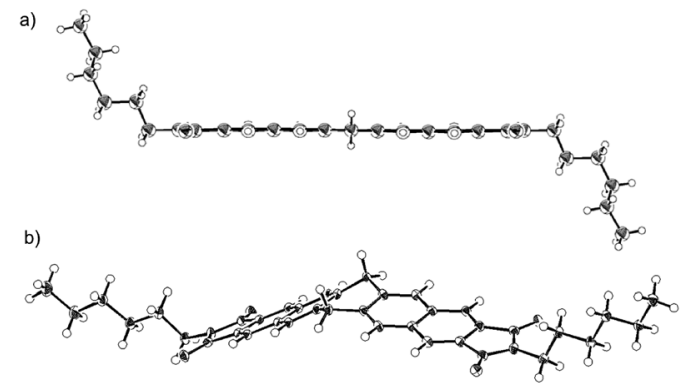

Fig. 3 ORTEP drawings of (a) $3 a_{(\text {planer) }}$ and (b) $3 a_{(v)}$ (thermal ellipsoids at $50 \%$ probability).

a THF solution revealed a V-shaped dihydropentacene skeleton with a bent central six-membered ring $\mathbf{3} \mathbf{a}_{(\mathrm{v})}$.

The energy difference between the planar and V-shaped conformers was examined using density functional theory (DFT) calculations on model compound $3^{\prime}$, which bears $\mathrm{H}$ atoms instead of alkyl chains. The $\mathrm{V}$-shaped conformer $\mathbf{3}^{\prime}{ }_{(\mathrm{v})}$ is by $4.0 \mathrm{kcal} \mathrm{mol}^{-1}$ thermodynamically more stable than the planar conformer $\mathbf{3}^{\prime}$ (planar). These results suggest a small energy difference between the two conformers. Consequently, the solid-state structure of $\mathbf{3 a}$ is most likely determined by packing forces in the crystal.

Interestingly, the phosphorchromaticity changes in the solid state were also triggered by photoirradiation $(>300 \mathrm{~nm})$; however, the reaction was limited to the surface of the specimen. The phosphorchromaticity switching rate was sensitive to the substituents on the dihydropentacene. Upon photoirradiation of solids $\mathbf{3} \mathbf{a}_{\text {(planar) }}$ and $\mathbf{3} \mathbf{b}\left(\lambda_{\mathrm{ex}}>300 \mathrm{~nm} ; \mathbf{1} \mathrm{h}\right)$, the apparent fluorescence color gradually changed from bright blue to red. In the case of $\mathbf{3}_{(\mathrm{v})}$ and $\mathbf{3 c}$, the apparent fluorescence color did not change, not even after two days of photoirradiation. To clarify the different reactivity of the planar and V-shape conformers of 3a, further DFT calculations were carried out. Fig. 4 shows the relevant Kohn-Sham molecular orbitals for the optimized structures of $\mathbf{3}_{\text {(planar) }}^{\prime}$ and $\mathbf{3}_{(\mathrm{v})}^{\prime}$. Both HOMOs are clearly localized on the $\mathrm{C}-\mathrm{H}$ bonds of the central six-membered ring and the two naphthalene units. Interestingly, the LUMO of $\mathbf{3}^{\prime}{ }_{\text {(planar) }}$ is notably less localized around the $\mathrm{C}-\mathrm{H}$ bond of the central six-membered ring than the LUMO of $\mathbf{3}^{\prime}{ }_{(\mathrm{v})}$. These results indicate that the excited state of $\mathbf{3} \mathbf{a}_{\text {(planar) }}$ favors the elimination of the $\mathrm{C}-\mathrm{H}$ protons of the central six-membered ring compared to the case of $3 \mathbf{a}_{(\mathrm{v})}$.

To evaluate the differences in photoreactivity depending on the substituents, the molecular arrangements in the crystals were investigated. None of the crystals contained any solvent in the lattice. The distances between the $\mathrm{H}$ (from the $\mathrm{C}-\mathrm{H}$ bonds of

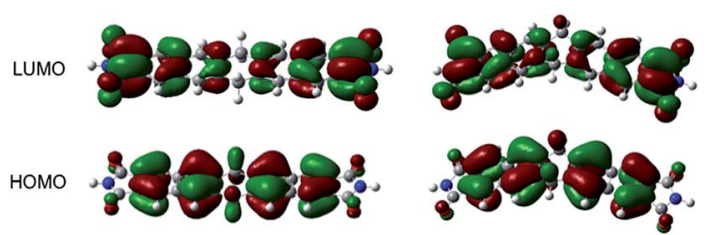

Fig. 4 Molecular Kohn-Sham orbitals of $\mathbf{3}^{\prime}{ }_{(\mathrm{v})}$ and $\mathbf{3}^{\prime}{ }_{\text {(planer), }}$ calculated at the M06-2X/6-31G* level of theory. the central six-membered ring) and $\mathrm{C}$ (from the naphthalene ring of the nearest-neighboring molecule atom) atoms were $c a$. $3.0 \AA$ (3a), $2.8 \AA$ (3b), and $3.3 \AA$ (3c). The long distance in the crystals of $3 \mathrm{c}$ should thus be unfavorable for hydrogen-atom transfer from the $\mathrm{C}-\mathrm{H}$ bond of the central six-membered ring to the naphthalene ring of the neighboring molecule.

\section{Conclusions}

$N, N^{\prime}$-Bisalkyl-6,13-dihydropentacene[2,3:9,10]biscarboxyimides 3a-c undergo disproportionation reactions in the solid state. The molecular structure and conformation in the crystals strongly influence the disproportionation reaction. Upon heating or photoirradiation of $\mathbf{3}$ in the solid state, the fluorescence color gradually changed from bright blue to red. The solid-state fluorescence behavior ${ }^{15}$ induced by disproportionation may serve as an example for guided molecular engineering, providing fascinating possibilities to tune materials for sensing, as well as optical and thermal recording applications.

\section{Experimental section}

\section{Instruments}

Unless otherwise stated, all experiments were performed under an atmosphere of argon. Solvents were dried by standard methods and distilled prior to use. $\mathrm{CDCl}_{3}$ was purchased from Cambridge Isotopes. NMR spectra were recorded on a JEOL JNM AL-300 or a Varian NMR System 600 spectrometer. The ${ }^{1} \mathrm{H}$ and ${ }^{13} \mathrm{C}$ NMR shifts are given in ppm relative to tetramethylsilane (TMS; $\delta=0 \mathrm{ppm}$ ) and referenced internally with respect to the residual proton $\left(\mathrm{CDCl}_{3}: \delta=7.26 \mathrm{ppm}\right)$, or the ${ }^{13} \mathrm{C} \mathrm{NMR}$ resonance of the solvent $\left(\mathrm{CDCl}_{3}: \delta=77 \mathrm{ppm}\right)$. UV-visible spectra were measured on a Shimadzu UV-3150 spectrometer. Emission and excitation spectra were recorded on a Jasco FP-6500 spectrometer, while IR spectra were obtained on a Thermo Nicolet IR Affinity-1 spectrophotometer. Thermogravimetric analysis (TGA) was performed on a Shimadzu DTG-60 in air. Wet column chromatography (WCC) was performed using Wakogel C-200. The melting points were determined on a MEL-TEMP micro melting point apparatus and are uncorrected. Reagents were purchased from Wako Pure Chemical Industries Ltd., Tokyo Chemical Industries Co., Ltd., Kanto Kagaku Co., Ltd., Nacalai Tesque Co., Ltd., and Aldrich Chemical Co. Pentacene-2,3,9,10tetracarboxylic acid (1) was prepared according to reported procedures. $^{8}$

\section{Synthesis of 2 and $3 a-c$}

Synthesis of 2 . Tetraacid 1 (267 $\mathrm{mg}, 0.59 \mathrm{mmol}$ ) was stirred for $3 \mathrm{~h}$ at $140{ }^{\circ} \mathrm{C}$ in acetic anhydride $(50 \mathrm{~mL})$. After cooling to room temperature, the solvent was removed in vacuo. The corresponding dianhydride (2) was obtained as a yellow solid (223 mg, $0.53 \mathrm{mmol}, 90 \%$ ). 2: $\mathrm{mp}>300{ }^{\circ} \mathrm{C}$; IR (KBr) 893, 1215, 1778,1836 , and $3464 \mathrm{~cm}^{-1}$. The low solubility of 2 prevented the recording of ${ }^{1} \mathrm{H}$ and ${ }^{13} \mathrm{C}$ NMR spectra.

Synthesis of 3a. A glacial acetic acid solution $(30 \mathrm{~mL})$ of 2 (150 mg, $0.357 \mathrm{mmol}$ ) and 1-aminohexane (108 mg, $1.07 \mathrm{mmol}$ ) 
was stirred for $12 \mathrm{~h}$ under reflux. After removal of the solvent, the residue was extracted several times with $\mathrm{CHCl}_{3}$. The organic layers were combined, washed with $\mathrm{HCl}$ ( $5 \mathrm{wt} \%$ in water) and brine, before being dried over anhydrous $\mathrm{MgSO}_{4}$. After filtration and removal of the solvent from the filtrate, the mixture was purified by WCC $\left(\mathrm{CHCl}_{3}\right)$ to give $3 \mathrm{a}(41.9 \mathrm{mg}, 0.071 \mathrm{mmol}, 20 \%)$ as colorless crystals. 3a ( $n$-hexane): $\mathrm{mp} 250{ }^{\circ} \mathrm{C}$ (decomp.); ${ }^{1} \mathrm{H}$ NMR (300 MHz, $\mathrm{CDCl}_{3}$ ): $\delta 0.88$ (brs, 6H), 1.33 (brs, 12H), 1.71 (brs, $4 \mathrm{H}), 3.74(\mathrm{t}, J=7.5 \mathrm{~Hz}, 4 \mathrm{H}), 4.36(\mathrm{~s}, 4 \mathrm{H}), 8.03(\mathrm{~s}, 4 \mathrm{H}), 8.30$ (s, 4H) ppm; ${ }^{13} \mathrm{C}$ NMR (75 MHz, $\mathrm{CDCl}_{3}$ ): $\delta 13.9(\mathrm{q}), 22.7(\mathrm{t}), 26.9$ $(\mathrm{t}), 28.7(\mathrm{t}), 31.8(\mathrm{t}), 37.4(\mathrm{t}), 38.5(\mathrm{t}), 123.5(\mathrm{~s}), 128.0(\mathrm{~s} \times 2), 134.4$ (d), 138.4 (d), 168.3 (s) ppm. Anal. calcd for $\mathrm{C}_{38} \mathrm{H}_{38} \mathrm{~N}_{2} \mathrm{O}_{4}: \mathrm{C}$, 77.79; H, 6.53; N, 4.77; found: C, 77.59; H, 6.41; N, 4.67.

Synthesis of $3 \mathbf{b}$. A toluene solution $(40 \mathrm{~mL})$ of $2(175 \mathrm{mg}$, $0.416 \mathrm{mmol}$ ) and 1-amino tridecane (839 $\mathrm{mg}, 4.16 \mathrm{mmol}$ ) was stirred for $6 \mathrm{~h}$ under reflux using a Dean-Stark trap. After removal of the solvent, the residue was extracted several times with $\mathrm{CHCl}_{3}$. The organic layers were combined, washed with $\mathrm{HCl}$ ( $5 \mathrm{wt} \%$ in water) and brine, before being dried over anhydrous $\mathrm{MgSO}_{4}$. After filtration and removal of the solvent from the filtrate, the mixture was purified by WCC $\left(\mathrm{CHCl}_{3}\right)$ to give $\mathbf{3 b}$ (100 mg, $0.139 \mathrm{mmol}, 30 \%$ ) as colorless crystals. $\mathbf{3 b}$ (tridecane): mp $250{ }^{\circ} \mathrm{C}$ (decomp.); ${ }^{1} \mathrm{H}$ NMR $\left(300 \mathrm{MHz}, \mathrm{CDCl}_{3}\right): \delta 0.87(\mathrm{t}, J=$ $6.0 \mathrm{~Hz}, 6 \mathrm{H}$ ), 1.23 (brs, 40H), 1.32 (brs, 4H), 3.72 (t, $J=6.0 \mathrm{~Hz}$, $4 \mathrm{H}), 4.35(\mathrm{~s}, 4 \mathrm{H}), 8.01(\mathrm{~s}, 4 \mathrm{H}), 8.28(\mathrm{~s}, 4 \mathrm{H}) \mathrm{ppm} ;{ }^{13} \mathrm{C}$ NMR $(75$ $\left.\mathrm{MHz}, \mathrm{CDCl}_{3}\right): \delta 14.1(\mathrm{q}), 22.7(\mathrm{t}), 28.6(\mathrm{t}), 29.2(\mathrm{t}), 29.3(\mathrm{t}), 29.4(\mathrm{t})$, $29.5(\mathrm{t}), 29.6(\mathrm{t}), 31.8(\mathrm{t}), 31.9(\mathrm{t}), 37.2(\mathrm{t}), 38.2(\mathrm{t}), 123.8(\mathrm{~s} \times 2)$, $134.4(\mathrm{~s}), 138.5(\mathrm{~s}), 168.1$ (s) ppm; UV-vis $\left(\mathrm{CHCl}_{3}\right): \lambda_{\max }=376(\varepsilon$ $=114$ 000), 305 (18 000), 365 (9000) nm; IR (KBr) 2956, 2922, 2828, 1770, 1708, $1392 \mathrm{~cm}^{-1}$. Anal. calcd for $\mathrm{C}_{52} \mathrm{H}_{66} \mathrm{~N}_{2} \mathrm{O}_{4}: \mathrm{C}$, 79.79; H, 8.50; N, 3.58; found: C, 79.53; H, 8.56; N, 3.55.

Synthesis of 3c. A toluene solution $(10 \mathrm{~mL})$ of $2(54 \mathrm{mg}, 0.128$ $\mathrm{mmol}$ ) and 1-amino-2-ethylhexane (171 $\mathrm{mg}, 1.28 \mathrm{mmol})$ was stirred for $6 \mathrm{~h}$ under reflux using a Dean-Stark trap. After removal of the solvent, the residue was extracted several times with $\mathrm{CHCl}_{3}$. The organic layers were combined, washed with $\mathrm{HCl}$ ( $5 \mathrm{wt} \%$ in water), before being dried over anhydrous $\mathrm{MgSO}_{4}$. After filtration and removal of the solvent from the filtrate, the mixture was purified by WCC $\left(\mathrm{CHCl}_{3}\right)$ to give $3 \mathrm{c}(53 \mathrm{mg}$, $0.083 \mathrm{mmol}, 64 \%$ ) as colorless crystals. 3c (2-ethylhexane): $\mathrm{mp}$ $281{ }^{\circ} \mathrm{C}$ (decomp.); ${ }^{1} \mathrm{H}$ NMR (300 $\left.\mathrm{MHz}, \mathrm{CDCl}_{3}\right): \delta 0.85-0.96(\mathrm{~m}$, $12 \mathrm{H}), 1.22-1.41$ (m, 16H), 1.88 (sept, $J=7.5 \mathrm{~Hz}, 2 \mathrm{H}), 3.63$ (d, $J=$ $7.5 \mathrm{~Hz}, 4 \mathrm{H}), 4.35(\mathrm{~s}, 4 \mathrm{H}), 8.02(\mathrm{~s}, 4 \mathrm{H}), 8.29(\mathrm{~s}, 4 \mathrm{H}) \mathrm{ppm} ;{ }^{13} \mathrm{C} \mathrm{NMR}$ $\left(75 \mathrm{MHz}, \mathrm{CDCl}_{3}\right): \delta 10.4(\mathrm{q}), 14.1(\mathrm{q}), 23.0(\mathrm{t}), 23.8(\mathrm{t}), 28.4(\mathrm{t})$, $30.5(\mathrm{t}), 37.3(\mathrm{t}), 38.2(\mathrm{~d}), 42.1(\mathrm{t}), 123.8(\mathrm{~s}), 127.7(\mathrm{~s}), 127.8(\mathrm{~s})$, 134.5 (d), 138.5 (d), 168.5 (s) ppm; IR (KBr) 2958, 2929, 2858, 1763, 1701, 1439, 1393, 1360, 1379, 1120, 947, 905, 746, 621, 579, and $480 \mathrm{~cm}^{-1}$. Anal. calcd for $\mathrm{C}_{42} \mathrm{H}_{46} \mathrm{~N}_{2} \mathrm{O}_{4}$ : C, 78.47; $\mathrm{H}$, 7.21; N, 4.36; found: C, 78.32; H, 7.28; N, 4.30.

\section{X-ray data collection}

Single crystals of $\mathbf{3 a - c}$ were grown by slow evaporation of saturated solutions of $\mathbf{3 a - c}$ in benzonitrile at room temperature. Single crystals of $\mathbf{3} \mathbf{a}_{(\mathrm{v})}$ were grown by slow evaporation of a saturated solution of $3 \mathbf{a}_{(\mathrm{v})}$ in THF at room temperature. The crystals were coated with hydrocarbon oil, mounted on glass fibers, and placed under a cold stream of $\mathrm{N}_{2}$ in the diffractometer. The intensity data for $\mathbf{3 a - c}$ were collected on a Rigaku VariMax diffractometer with a Saturn CCD detector using graphite-monochromated Mo-K $\alpha$ radiation $(\lambda=0.71071 \AA)$ up to $2 \theta_{\max }=50^{\circ}$ at $103 \mathrm{~K}$. All structures were solved by Patterson methods (SHELXS-97) ${ }^{16}$ and refined by full-matrix least-squares procedures on $F^{2}$ for all reflections (SHELXL-97) ${ }^{17}$. All hydrogen atoms were located following AFIX instructions. All other atoms were refined anisotropically. CCDC-1911683 (3a $\mathbf{a}_{\text {(planar) }}$ ), CCDC$1911685\left(3 \mathbf{a}_{(\mathrm{v})}\right)$, CCDC-1911684 (3b), and CCDC-1911686 (3c) contain the supplementary crystallographic data for this paper.

$3 \mathrm{a}_{\text {(planar) }}: \mathrm{C}_{38} \mathrm{H}_{38} \mathrm{~N}_{2} \mathrm{O}_{4}, \mathrm{MW}=586.70$, triclinic, space group $P \overline{1}$ (\#2), $a=4.755(15) \AA, b=6.057(19) \AA, c=27.46(9) \AA ㅇ=$ 86.36(9) ${ }^{\circ}, \beta=89.245(10)^{\circ}, \gamma=84.00(6), V=785(4) \AA^{3}, Z=1$, $D_{\text {calcd }}=1.241 \mathrm{~g} \mathrm{~cm}^{-3}, \mu=0.080 \mathrm{~mm}^{-1}, R_{1}(I>2 \sigma(I))=0.0616$, $\mathrm{w} R_{2}$ (all data) $=0.2120, T=103(2) \mathrm{K}, \mathrm{GOF}=1.051$.

$3 \mathrm{a}_{(\mathrm{v})}: \mathrm{C}_{80} \mathrm{H}_{84} \mathrm{~N}_{4} \mathrm{O}_{9}, \mathrm{MW}=1245.51$, triclinic, space group $P \overline{1}$ (\#2), $a=4.483(3) \AA, b=16.529(1) \AA, c=21.775(13) \AA, \alpha=$ $85.587(10)^{\circ}, \beta=88.775(17)^{\circ}, \gamma=87.293(12), V=1074.5(11) \AA^{3}$, $Z=1, D_{\text {calcd }}=1.287 \mathrm{~g} \mathrm{~cm}^{-3}, \mu=0.074 \mathrm{~mm}^{-1}, R_{1}(I>2 \sigma(I))=$ $0.045, \mathrm{w} R_{2}$ (all data) $=0.1036, T=103(2) \mathrm{K}, \mathrm{GOF}=1.031$.

3b: $\mathrm{C}_{52} \mathrm{H}_{66} \mathrm{~N}_{4} \mathrm{O}_{4}, \mathrm{MW}=783.07$, triclinic, space group $P \overline{1}(\# 2)$, $a=4.638(2) \AA, b=9.316(5) \AA, c=24.909(14) \AA, \alpha=$ 91.5765(12) $)^{\circ}, \beta=91.622(12)^{\circ}, \gamma=92.166(15), V=1074.5(11) \AA^{3}$, $Z=1, D_{\text {calcd }}=1.210 \mathrm{~g} \mathrm{~cm}^{-3}, \mu=0.075 \mathrm{~mm}^{-1}, R_{1}(I>2 \sigma(I))=$ $0.0491, \mathrm{w} R_{2}$ (all data) $=0.1352, T=103(2) \mathrm{K}, \mathrm{GOF}=1.073$.

3c: $\mathrm{C}_{42} \mathrm{H}_{46} \mathrm{~N}_{4} \mathrm{O}_{4}, \mathrm{MW}=642.81$, triclinic, space group $P \overline{1}(\# 2)$, $a=7.451(5) \AA, \quad b=8.965(5) \AA, c=14.802(12) \AA, \alpha=78.46(5)^{\circ}$, $\beta=84.78(5)^{\circ}, \gamma=63.33(4), V=865.7(11) \AA^{3}, Z=1, D_{\text {calcd }}=$ $1.233 \mathrm{~g} \mathrm{~cm}^{-3}, \mu=0.079 \mathrm{~mm}^{-1}, R_{1}(I>2 \sigma(I))=0.0476$, w $R_{2}$ (all data $)=0.1264, T=103(2) \mathrm{K}, \mathrm{GOF}=1.059$.

\section{Conflicts of interest}

The authors declare no conflicts of interest.

\section{Acknowledgements}

This work was partially supported by JSPS KAKENHI Grants $15 \mathrm{H} 03519$ (Y. T.), 16K05895 (T. T.), $18 \mathrm{H} 04430$ in Middle Molecular Strategy (A. O.) and 18K05134 (A. O.), 19K15574 (Y. O.), Okayama Foundation of Science and Technology (Y. O.), Promotion and Mutual Aid Corporation for Private Schools of Japan (Y. O.) and OUS Research Project (OUS-RP-19-4 to A. O. and Y. O.). The authors (A. O. and Y. O.) thank to Research Instruments Center, Okayama University (JNM-ECS400 and JNM-ECZ400).

\section{Notes and references}

1 S. E. Stein, L. L. Griffith, R. Billmers and R. H. Chen, J. Org. Chem., 1987, 52, 1582.

2 L. B. Roberson, J. Kowalik, L. M. Tolbert, C. Kloc, R. Zeis, X. Chi, R. Fleming and C. Wilkins, J. Am. Chem. Soc., 2005, 127, 3069.

3 (a) M. Gerst and C. Rüchardt, Tetrahedron Lett., 1993, 34, 7733; (b) F. Schaffer, H.-D. Beckhaus, H.-J. Rieger and 
C. Rüchardt, Chem. Ber., 1994, 127, 557; (c) M. Gerst, H.-D. Beckhaus, C. Rüchardt, E. E. B. Campbell and R. Tellgmann, Tetrahedron Lett., 1993, 34, 7729; (d) C. Rüchardt, M. Gerst, J. Ebenhoch, H.-D. Beckhaus, E. R. B. Campbell, R. Tellgmann, H. Schwarz, T. Weiske and S. Pitter, Angew. Chem., Int. Ed. Engl., 1993, 32, 584; (e) M. Gerst, H.-D. Beckhaus, C. Rüchardt, E. R. B. Campbell and R. Tellgmann, Tetrahedron Lett., 1993, 34, 7729; (f) N. Naghizada, G. H. C. Prado and A. de Klerk, Energy Fuels, 2017, 31, 6800.

4 (a) C. Rüchardt, M. Gerst and M. Nölke, Angew. Chem., Int. Ed. Engl., 1992, 31, 1523; (b) M. Coellen and C. Rüchardt, Chem.-Eur. J., 1995, 1, 564; (c) C. Höfler and C. Rüchardt, Liebigs Ann., 1996, 183.

5 K. Rakus, S. P. Verevkin, J. Schätzer, H.-D. Beckhaus and C. Rüchardt, Chem. Ber., 1994, 127, 1095.

6 H. Friebolin and C. Rüchardt, Liebigs Ann., 1995, 1339.

7 (a) C. Rüchardt, M. Gerst and J. Ebenhoch, Angew. Chem., Int. Ed. Engl., 1997, 36, 1406; (b) J. A. Franz and D. M. Camaioni, J. Org. Chem., 1984, 49, 3563; (c) M. Gerst and C. Rüchardt, Chem. Ber., 1993, 126, 1039; (d) F. Payan and A. de Klerk, Energy Fuels, 2018, 32, 9340.

8 (a) T. Tajima, A. Yamakawa, K. Fukuda, Y. Hayashi, M. Nakano and Y. Takaguchi, Chem. Lett., 2012, 41, 2702; (b) H. Shirai, T. Tajima, K. Kubo, T. Nishihama, H. Miyake and T. Takaguchi, Bull. Chem. Soc. Jpn., 2016, 89, 437; (c)
K. Kubo, T. Tajima, H. Shirai, T. Nishihama and T. Takaguchi, ChemistrySelect, 2017, 8, 2452.

9 K. Baathulaa, Y. Xu and X. Qian, J. Photochem. Photobiol., A, 2010, 216, 24.

10 H. Yamada, Y. Yamashita, M. Kikuchi, H. Watanabe, T. Okujima, H. Uno, T. Ogawa, K. Ohara and N. Ono, Chem.-Eur. J., 2005, 11, 6212.

11 B. Manna, R. Ghosh and D. K. Palit, J. Phys. Chem. C, 2016, 120, 7299.

12 K. B. Lipkowitz and P. W. Rabideau, J. Org. Chem., 1982, 47, 1002.

13 J. Shi, D. Wu, Y. Ding, D. Wu, H. Hu and G. Lu, Tetrahedron, 2012, 68, 2770.

14 (a) D. Lehnherr, A. H. Murray, R. McDonald and R. R. Tykwinski, Angew. Chem., Int. Ed., 2010, 49, 6190; (b) W. Liu, Y. L. Tnay, K. P. Gan, Z. Liu, W. H. Tyan and K. Narasaka, Helv. Chim. Acta, 2012, 95, 1953.

15 C. Yuan, S. Saito, C. Camacho, S. Irle, I. Hisaki and S. Yamaguchi, J. Am. Chem. Soc., 2013, 135, 8842.

16 G. M. Sheldrick, SHELX-97, Program for the Refinement of Crystal Structures, University of Göttingen, Göttingen, Germany, 1997.

17 G. M. Sheldrick, SHELXL-97, Program for the Refinement of Crystal Structures, University of Göttingen, Göttingen, Germany, 1997. 